SF 991
.$\$ 85$ 



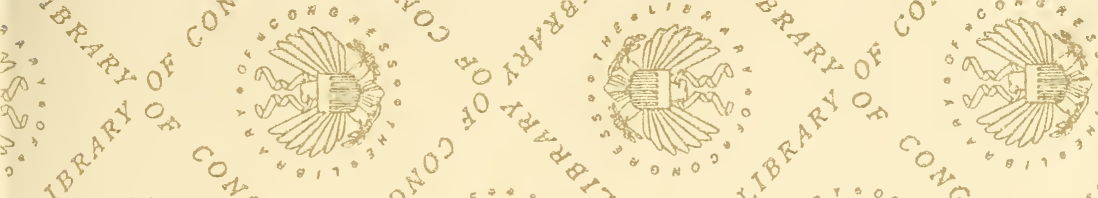

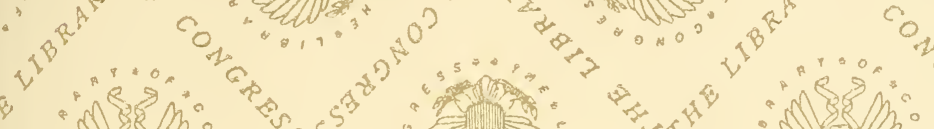

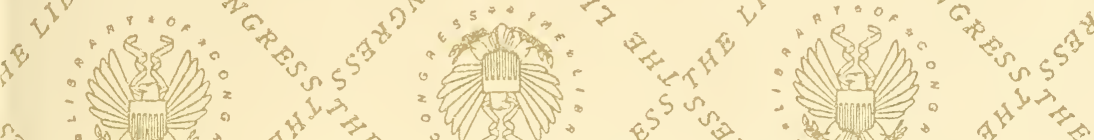

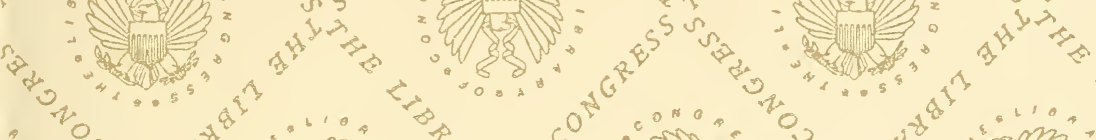

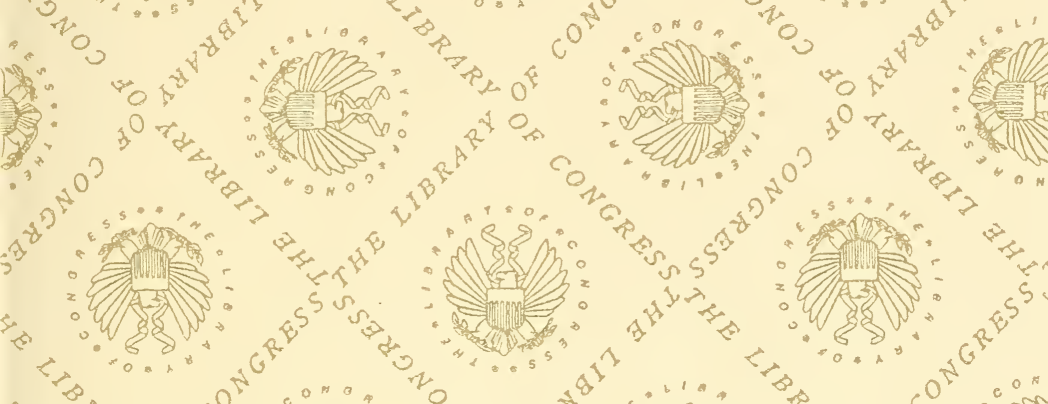

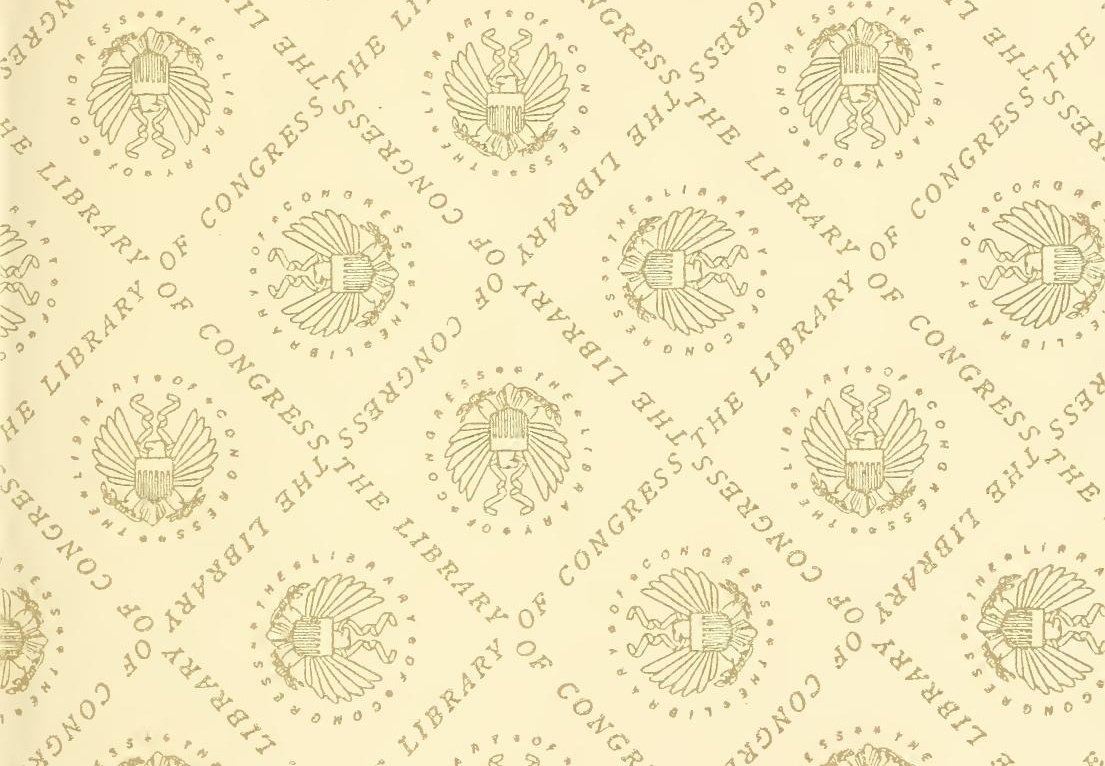

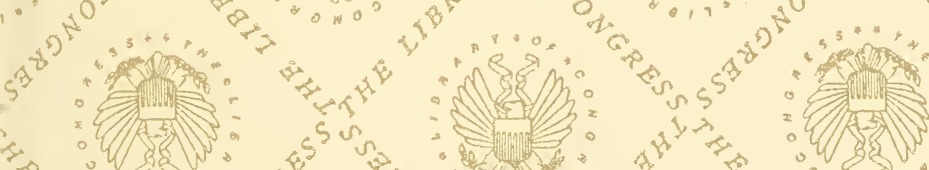
s

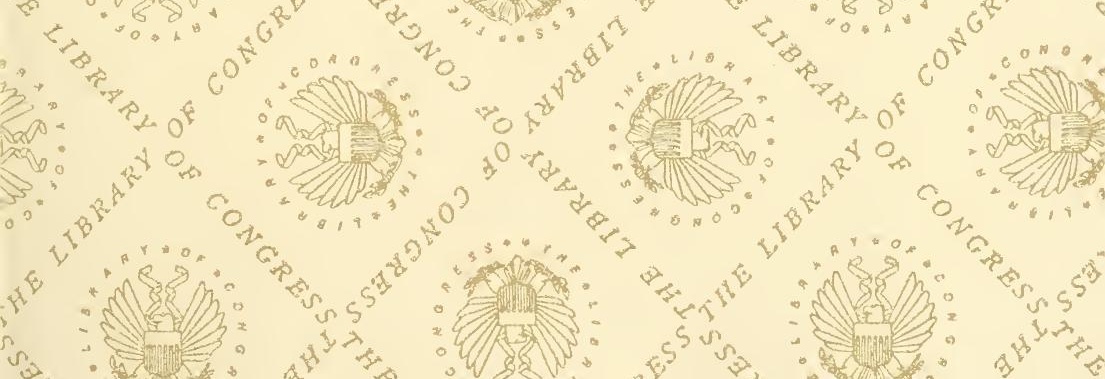







\section{CANINE DISTEMPER}

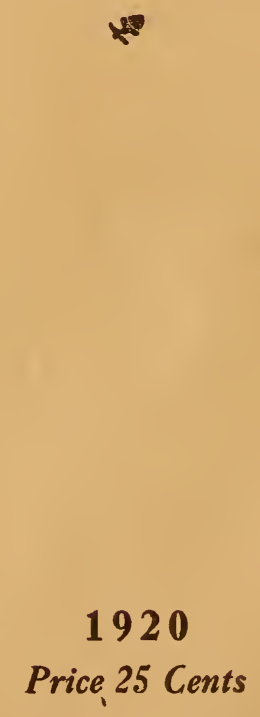





\section{CANINE DISTEMPER}

Charles Stout

1920

THE DELSON GHEMICAL COMPANY, Inc. NEW YORK 


\title{
.
}

THE author takes this opportunity 直 of acknowledging the material assistance and cooperation which he has received from many sources in the preparation of the following pages.

\section{Copyright 1920 , by}

The Delson Chemical Company, Inc.

\section{FEB 191920}

\author{
(C) $\operatorname{Cl} 4563155$
}




\section{Foreword}

$\mathrm{O}^{\prime}$

$F$ all the scientific achievements which mark the advance of civilization, none could be of greater value than a method whereby disease can be brought under control. Health is our greatest asset. The average citizen would willingly give up many of our modern conveniences in return for the assurance of the perfect health of himself and his family. The announcement, therefore, that we have brought a disease of the nature of canine distemper under control, will be of general interest, not only because of the control of the disease itself but because this infection belongs to a group or class of diseases, in which are included our influenza and pneumonia, which have hitherto baffled all attempts at successful treatment.

The defensive mechanism by which the body combats disease is the same in all warm blooded animals. The part played by the cow, the rabbit and the horse in the treatment of such diseases as small pox, rabies and diphtheria is well known. The old saw "try it on the dog" has become the basis of our modern research work.

Thirty years ago disease was a mystery. The physician was guided mainly by the symptoms. Little was known of its cause beyond the fact that certain diseases could be traced to germs. In many of our common infections the cause was unknown. Since the announcement of an effective antitoxin against the diphtheria bacillus, great strides have been made in bacteriology. We now have a fairly complete knowledge of the life history of the various infecting agents which cause disease and we are also able to recognize and identify those substances in the body which resist infection. With this knowledge has come the realization that disease is more powerful than the curative powers of the body and that nature's forces are unable to cope with disease in virulent form.

Medical science has advanced very rapidly in recent years. 
Many of the beliefs that were accepted ten years ago have been discarded. So rapid has been the advance in medical knowledge that considerable confusion has arisen. It has been difficult for the busy practitioner to follow the immense amount of research work that is being carried on, much of which, it must be admitted, has been unprofitable. Some of the knowledge gained during the war period has not yet been disseminated. It will be well, therefore, before proceeding with a discussion of distemper, to review briefly our modern understanding of disease from the time infection occurs until the final triumph of the curative forces.

\section{The Germs of Disease}

In any discussion of infectious disease a knowledge of germ life is necessary. In the early days of serum therapy, when it was discovered that a small amount of serum, derived from a horse which had been inoculated with the diphtheria bacillus, would protect the human being against the specific toxin of the disease, it was thought that it would be but a short time before successful treatments could be prepared from the germs of other diseases. With the many forms of terrestrial life before their eyes, it seems incredible that investigators should suppose that all germ life was fashioned after the same pattern. We now know that there is a great variety in the pathogenic organisms which cause disease and that many of them do not yield to serum therapy.

The germs of our common diseases may be divided into three general classes:

First. The NECROPARAsites. These germs are possessed of a very low grade of infectiousness, that is, the power to multiply and spread through the body, but kill through their highly fatal poisons. The diphtheria and tetanus bacilli are typical. While the germs may be unable to maintain themselves in normal tissue, their toxins are powerful enough to kill even after the germs themselves have ceased to exist. Production of their poisons* ends with the germs. Thus the toxins are limited and can be controlled by an antitoxin.

Second. The TRUE Parasites. This group of organisms is highly infectious and aggressive, but the infection is accompanied by little or no toxic effect. An example is the

-This includes the endotoxins which are set free after the disintegration of the microorganisms. 
anthrax bacillus. Manifestation of disease is often lacking, although the blood of the infected animal may be swarming with the organisms. Thus the infection may be far advanced before a warning is given.

Third. The semiparasites. Between these two groups are the semiparasites. They are infectious and aggressive and multiply rapidly in the system. They also produce a poison which, though not as deadly as the toxins of the necroparasites, is an important factor in the development of the infection. These are the germs with which we have to deal in canine distemper and in some of the most serious human diseases as influenza. Successful treatment requires the destruction of the offending organisms. The toxins are not limited, as in the case of the first group, each new germ adding to the poisons in the system. Were it possible to bind all the toxins at any period of the disease, in a short time a new generation of organisms would produce new toxins. An antitoxin, therefore, is not effective.

Besides these three groups, there are many transition forms of organisms and, in addition, the Tissue Parasites.

\section{Deíensive Forces}

The forces which nature has at its disposal to combat disease may be divided into two classes, those which are available at the time the infection occurs and those which develop as the direct result of the infection. In the first class are the bactericidal power of normal serum and the power of the white blood corpuscles and other phagocytes to ingest disease germs once they have broken through the outer covering of the body and entered the system. Normal serum contains opsonins which prepare the invading organisms for phagocytosis. A lowering of the opsonic content of the blood predisposes an animal to disease.

In the second class are the various bacteriolytic and antitoxic antibodies which are liberated by the cells after disease has found a footing in the system. Various theories have been advanced as to how this phenomenon occurs, notably Ehrlich's side chain theory. Ehrlich's conception of antibody formation has passed many corroborative tests. His doctrine is important to the study of distemper, for, if we accept the side chain theory, it is possible to demonstrate that the infection can prevent the formation of antibodies, 
thus depriving the animal of its main defense against disease. This fact a!one would account for the very high death rate in distemper.

The cells are the active basis of all animal organization. According to Ehrlich's doctrine, a cell is composed of a central nucleus upon which the life and activity of the cell depends, attached to which are a variable number of subsidiary mouths or receptors (side chains) by which the nutrition of the cell is røgulated. These receptors differ from each other in certain chemical affinities, according to the nature of the food molecules to be absorbed by the cells. The many different body cells (for example, the blood cells, the nerve cells, the muscle cells) varying in nutritional requirements, account for a considerable variation in the receptors. Ehrlich conceives that toxin molecules may accidently possess the same affnity for certain receptors as the food molecules they are accustomed to receive under normal conditions. To the possibility that different disease germs are attracted by a different set of side chains is attributed the specific immunity which follows various infections. When infection occurs the germ or its toxin becomes affixed to a receptor with the result that not only is the cell deprived of necessary nourishment but injury or complete destruction may follow. The cell rids itself of this condition by casting off the receptor, and its loss stimulates the regenerative cell activity to replace the damage. According to Weigert's theory, the defect in the cell structure is repaired above the necessary measure. Each individual receptor which the cell loses is replaced by numerous mouths, of which the fittest will remain with the mother cell, the remainder being cast off into the blood circulation, where they act as antibodies. The same law of regeneration is common in the vegetable kingdom. If a limb is removed from a tree, many small branches will spring forth to supply the requirements of the roots, the most favored branch crowding off the others, just as in the development of these new mouths, some are cast off. The free receptors (antibodies) have the same affinity for the toxin molecules as those attached to the cells. They combine with the germs and their toxins and render them harmless. It is signifcant that Ehrlich, having attained this knowledge of the body's defensive forces, turned to chemotherapy. 


\section{Distemper}

CANINE distemper is a semiparasitic infection. It is highly contagious. On account of the widespread distribution, frequent recurrence and high death rate it ranks as one of, if not the most serious infectious disease. The germ of distemper is a fixed and volatile virus which is easily held in suspension in the atmosphere. Under suitable atmospheric conditions it may be carried to a distance and is readily transmitted $\mathrm{k} y$ animate or inanimate objects. It enters the system through the nose, mouth or eyes.

Cause. Much research work has been done to determine the specific organism of distemper. In 1910 Ferry isolated a short narrow bacillus which he called the Bacillus Bronchisepticus. This bacillus is found in all organs of the body. Other observers, especially Torrey, corroborated Ferry's findings. The same bacillus, and many other organisms, are described by other investigators. They may be here given briefly:

Bacillus Bronchisepticus, bi-polar, solitary or in pairs (Ferry, McGowan, Torrey, Rahe and Scott). Bacillus of Distemper, small dagger shaped bacillus (Semmer and Jess). Pasteurella Canis, bi-polar (Lignieres, Cadiot, Breton). Short rod bacillus (Wunscheim). Staff bacillus (Piorkowski). Short motile bacillus (Babes and Bazanesco). Coli (Jensen and Mari). Cocci, in groups or chains (Rabe). Diplococcus (Martin, Mathis, Legrain, Jacquet, Taty and Jacquine). Streptococcus (Jensen). Staphylococcus (Zelinski, Neucki and Karapinski). Micrococcus producing skin eruption, bronchopneumonia and gastro-enteritis (Marcone, Meloni and Casol). Ovoid Bacillus (Galli-Valerio, Petropawlowski and Ceramicola).

It is probable that the Bacillus Bronchisepticus is the cause of distemper and that the other bacteria contribute to the severity and fatality of the disease.

Whatever the cause, the symptoms are well marked and 
vary greatly according to the organs affected. Three types of the disease are recognized; respiratory, gastroenteric and nervous. These subdivisions have grown out of the old method of symptomatic treatment and are not entirely accurate. Involvement of the nervous system includes the nerves controlling digestion, resulting in the impairment of the digestive organs and the consequent weakening of the whole system, exposing the lungs and bronchi to further infection. Some authorities include a fourth type, exanthematical or pustular distemper. This manifestation, however, is more properly classed as a secondary infection.

Syмртомs. At first the dog appears dull and languid with little inclination for food. The nose is moist and cold and soon becomes hot and dry. As the symptoms develop, a watery discharge from the eyes and nose appears, accompanied by sneezing, fever, shivering. The temperature rises to about $105^{\circ} \mathrm{F}$. or over, but varies with the severity of the disease, sometimes becoming subnormal. Gastric disturbances are evidenced by a husky cough, retching, vomiting and diarrhoea, the excretions sometimes mixed with blood and traces of intestinal mucosa. As the disease progresses, the discharge from the eyes and nose becomes purulent, the teeth are coated and the breath offensive. There is rapid emaciation, even though a fair amount of nourishment is taken. The eyelids become inflamed and swollen, the breathing labored, the inclination for warmth more evident and the prostration greater.

When the nervous system becomes involved the dog appears depressed. This condition may be varied by short periods of restlessness and excitement. The eyes become congested and the muscles over the forehead throb and twitch. This is followed by a twitching of the muscles of the extremities, the lower jaw and legs, weakness of the hinder parts and a partial or general paralysis. Impairment of the nerves in the region of the intestines is not clearly indicated and must be anticipated. Loss of appetite and general intestinal derangement should be looked upon with suspieion.

At times the foregoing symptoms are accompanied by pustular eruptions, particularly on the abdomen and the inner surface of the thighs. In some cases many of these symptoms are absent. The dog may have, apparently, a very light case and suffer little inconvenience from the malady. 
Vigilance should not be relaxed on this account. Sudden and rapid changes are common in distemper and a change for the worse may come without warning.

Prognosis. Before the days of chemotherapy the prognosis of distemper was generally considered unfavorable. The United States Department of Agriculture estimated the death rate at fifty per cent.

Under the old therapy there were two reasons for a fatal termination in distemper: first, a lowered resistance of the body; second, an increased virulence of the infection. In distemper, as in many other diseases, the virulence of the organisms, especially during epidemics, is frequently greater than the most robust constitution is able to combat with the curative forces which nat!re provides. Virulence in the semiparasites may be defined as increased ability of the invading organisms to multiply in the infected animal. Greater injury and a more rapid progression of the infection follow as a consequence. Let us see what this power is and how it occurs.

VIRULENCE. If a puppy is ill fed, badly housed and closely confined-in other words, raised under unnatural conditionsit will grow up a weak little runt that will likely fall a prey to the first infection. On the other hand, a puppy which is well fed and given plenty of exercise will grow to maturity in full possession of the natural forces which resist disease.

Now let us suppose that puppy No. 2 is placed in a kennel in which an outbreak of distemper occurred the year previous and in which some of the germs still remain. These germs have been out of their natural habitat for a considerable period. They have been exposed to frequent changes of temperature and atmosphere and have lost considerable vitality, in other words, they have become attenuated. When puppy No. 2 comes down with distemper a weakened germ is combated with the full power of resistance of perfect health. The infection progresses with difficulty and the puppy comes easily through the disease.

The germs are carried to a neighboring kennel where there is a litter of puppies of the first type. Here they find a host in which conditions are more suitable for development. Having passed through this kennel, they emerge with their aggressivity greatly increased and in a condition to overcome a stronger resistance than any hitherto encountered. And so, in passing from one dog to another, the organisms 
acquire, not only powers of offense, but increased resistance to nature's defensive forces, until eventually they attain a degree of virulence beyond anything in the power of nature to combat. The reverse may also occur.

Until we have a more definite knowledge of the germs causing distemper, we can only speak of the defensive and offensive forces of the microorganisms in general terms. Many forms of pathogenic organisms have the power of forming capsules, or of thickening their outer surface. Whether or not the capsule is actually, in a sense, a defensive armor has not been definitely determined. The fact remains that capsule formation is evidence of increased virulence. Germs may also protect themselves against the action of drugs or sera by casting off the receptors through which the bactericidal action of these agents is communicated to the life of the organism.

Toxins*. With a higher order of virulence the increased power of the distemper toxins play an important part in the development of the infection, protecting the germs from attack, by weakening the defensive forces of the host and rencering the conditions suitable for rapid multiplication of the bacteria. This may be accomplished directly, by the action of the toxins on the cells themselves or indirectly, by the effect of the toxins on the organs. In the direct toxic effect we see a deterrent influence on the phagocytic action of the white blood corpuscles and injury to the cells which renders antibody formation more difficult.

The indirect effect of the distemper toxins on the canine system is none the less fatal; it, in fact, constitutes one of the most serious phases of the disease. Clinicians have long been familiar with the effect of various infections of this character upon the intestines and lungs. Realizing the close interaction between the various organs, injury to the body's defensive forces is to be expected as a consequence. Chemotherapy has added materially to our knowledge of these phenomena. With the perfecting of the chemical germicide, it has become possible to eliminate the infection at any point of the disease. Thus we can measure these disturbances and note their progression at the various stages of the infection.

... * The -injuries attributed to toxic effect may also occur through the activities of the microorganisns themiselves, the toxins assisting. 
Distemper is notorious for disturbances of the intestinal tract. Some impairment of digestion must be expected under these conditions. By the employment of the chemical germicide it has been possible to demonstrate that this impairment occurs very early in the disease, even before dangerous symptoms appear, and results, in some cases, in complete suspension of the gastro-intestinal functions. The rapid emaciation, so often seen in distemper, is thus satisfactorily accounted for by starvation. We give here briefly our observations by which this was determined.

The germicide Delcreo is readily absorbed by the digestive organs. Under the most favorable circumstances a complete saturation of the system can be obtained by oral dosage in from twelve to fourteen hours. If treatment has been prompt and thorough, clinical evidence of the infection ends shortly afterwards. And yet, at the beginning of our researches, there were many cases of distemper which did not respond to treatment. From this it appeared that the animal's digestive organs were not functioning. This we were able to prove, for on the administration of a stimulant (whiskey or brandy) similar cases responded promptly.

In seeking an explanation for impaired digestion two theories suggest themselves. First, the effect of the toxins on the intestinal membranes; second, injury to the controlling nerves. The evidence is in favor of the latter, for the reason that while intestinal infiammation is common in distemper and is clearly indicated by symptoms, in many of our cases these symptoms were entirely absent, the animals in some instances showing little evidence of being ill. In the light of the Ehrlich doctrine, it would seem, that intestinal impairment has a very direct effect on antibody formation. With the loss of their nutriment, not only are the cells weakened but even the incentive for the formation of the new mouths no longer exists.

Injury to the lungs results in faulty oxygenation and injury to all the cells of the body through the accumulation of waste products. The recent pandemic of influenza afforded the opportunity of observing this phase of these infections* for in this instance influenza approached closely the virulence

\footnotetext{
*Influenza closely resembles canine distemper in etiology, symptoms and progression. The successful results obtained in the treatment of distemper with a chemical germicide have been duplicated in influenza and pneumonia in humans and our findings verified by practitioners in these diseases.
} 
so common in distemper. With the aid of chemotherapy it was possible to stamp out the virulent influenza infection within fourteen hours of first symptoms. Nevertheless, during that short period the injury to the lungs had so far advanced that inflammation could be demonstrated forty-eight hours afterwards.

Complications. The danger of a fatal termination in distemper is increased by secondary infections of which the most serious is pneumonia. We have seen the effect of distemper on the lungs. The resulting inflammatory or catarrhal condition of these organs offers fertile media for pneumococci and streptococci invasion. On account of the animal's weakened condition it is highly fatal.

The pyogenic infection often causes a serious complication. The infection may be present in the system in a mild form before the onset of distemper and develops in severity with the disease. This, in a measure, accounts for the early appearance of the pustular eruptions in some cases and not in others. This complication assumes a serious phase in the later periods of the disease, when the animal's body has been weakened by the strain of the primary infection. Dogs frequently succumb to the internal abscesses after they have reached the convalescent stage.

Chorea, a common sequel of distemper, may sometimes be classed as a complication because of the additional strain imposed upon the nervous system. It is the result of the action of the distemper toxins on the nerve cells. It follows more often an anaemic condition.

The germicide has eliminated much of the danger of complications. 


\section{Treatment}

GINCE the earliest days of medical science the cure of $\checkmark$ disease has been accomplished by the curative powers of the body. That nature's forces so of ten fail should not be construed that nature's methods are faulty, it denotes but the limitation of our physical powers. Nature's law is the survival of the fittest. In other sciences man has improved on nature's methods. This principle is now applied to the control of disease.

Medical progress has been necessarily slow, because of its dependence on the development of subservient sciences, as biology, anatomy, bacteriology, chemistry and others. It is only within the last generation that we have had a fairly accurate knowledge of the agents of infection. We are only just beginning to appreciate the significance of virulence. During the pandemic of influenza of 1918, methods of control were attempted which had been abandoned in the treatment of distemper because they failed in the virulent cases. Virulence is very common in distemper, yet there is no means of telling at the onset how powerful an infection we have to combat. We have, therefore, come to look upon all distemper cases as virulent cases and these the chemical germicide alone has the power to control.

The dog has always been the trusted friend of man. We have cause to be grateful for his services when in full possession of his health and vigor. How much more grateful should we be since, in the time of his adversity, he has pointed out the way to control disease.

In the development of chemotherapy we have profited from the experience gained in other methods. It will be well. therefore, to give some consideration to medication and serum therapy before discussing treatment by germicide.

\section{Medication}

Drugs are used to reduce fever, to relieve pain, to correct 
intestinal disorders or to stimulate activity in some organ; but the febrifuge, the cathartic or stimulant is employed merely to relieve the animal of some of the strain which distemper imposes; it is nature alone which effects the cure. It is true that some of the drugs of the older Pharmacopoeia as creosote, quinine or mercury, have germicidal properties, but these are not sufficiently available to materially change the situation. Like the others, they but influence the course of the infection. The one exception, if exception there be, is alcohol, by counteracting the distemper toxins.

In 1917 the House of Delegates of the American Medical Association condemned the use of alcohol in a resolution stating "its use in therapeutics as a tonic or stimulant or for food has no scientific value." In 1918 the officers and members of this Association, in the uniform of the United States Army, were, figuratively, pouring whiskey into the concentration camps in the fight against influenza.

Alcohol has been generally used in distemper, and well known distemper "cures" contain as much as twenty-five per cent. It is of value for its influence on digestion. In dilute solutions it promotes the flow of saliva and the gastric juice and increases the vascularity of the gastric mucosa. After absorption it acts as a sedative on the nervous system and reduces the strain on the nerves. It also has the value of sparing tissue, thus replacing nutrients. Habit forming properties and the danger of overindulgence cannot be urged as excuses for depriving the dog of alcoholic medication.

\section{Vaccines and Serums}

Serum therapy has been of great value in the study of infectious disease. It has been an effective aid in diagnosis and has been employed with more or less practical results in the prevention and the control of some infections. From the scientific standpoint it has suffered from the overenthusiasm of its paid advocates, who would make it a cure-all. For it must be remembered, that serum therapy is but the bringing into play, through artificial means, of the same forces which the body produces naturally. It is therefore subject to nature's limitations. It has been of little value in distemper. After a thorough test, both scientifically and commercially, it has been very generally discarded for more modern methods. 
VACCINEs for Prevention. When a dog has passed through distemper it becomes immune from further attack. The immunity thus acquired is generally permanent but may be broken down if the system becomes debilitated.

Immunity arises first from antibodies which are present in the system in great numbers for a period following convalescence. It is not supposed however, that these antibodies always remain, but once having passed through the disease, the cells respond more readily to further infection.

Science has been able, in some diseases, to bring about antibody formation by inoculation with bacteria which have first been rendered harmless, but the immunity which follows is not permanent nor can it always be relied upon.* In some diseases there are several strains of the infecting organisms. Inoculation with one strain gives little or no protection against infection by the others. This has added to the difficulty of successful vaccination. It must not be lost sight of that distemper is a mixed infection.

Preventive inoculation in distemper is similar to the methods employed in typhoid. The cultures are either killed, or so far attenuated, as to preclude the danger of a general infection. Living vaccines are preferred, because during the short time the cultures remain alive in the system, they may be able to secrete some of their metabolic products. Torrey in his experiments used cultures of the B. bronchisepticus only; others have used a mixed vaccine containing cultures of bronchiseptici, streptococci and staphylococci. Torrey advises three inoculations at intervals of ten days and reinoculation every six months. Vaccination against distemper, sometimes results in inpairment of the nervous system. Chorea or loss of the sense of smell have resulted. The latter in a hunting dog is almost as serious, from the owner's standpoint, as the loss of the animal's life.

Vaccination may be advisable if the dog is to be entrusted to inexperienced hands for any considerable time. The anirnal should be in perfect condition. It must not be inoculated while exposed to distemper.

During the world war preventive inoculation against typhoid, which has hitherto been considered the most dependable of our modern preventive treatments, gave unsdtisfactory results probably due to the strain of war conditions. There were outbreaks of typhoid among the vaccinated. This was particularly noticeable in the American Arriny because of the high degree of immunity previously obtained from preventive inocilation, and in the Italian outbreak because of the high death rate. Italian-statistics show that the mortality aming the vaccinated for the two years 191.7 and 1918 was $21.7 \%$. as agaimst $20 \%$ in the unvaccinated. 
Curative Serumis. There are two forms of distemper sera in use today. The first is, more properly speaking, a curative vaccine and is similar to that employed in prevention. While it may in some cases hasten antibody formation, it is possible that some of the serum may combine with antibodies already formed and render them inactive. The second is an antiserum containing antibodies already formed. This is obtained from a suitable animal which has been inoclated with a series of injections of the distemper bacteria. This may be of value if administered in the early stages or before the infection has become general. Its action is, however, dependent upon the resistance of the microorganism. The success of serum as a curative agent in infections of the necroparasites and its failure in semiparasitic infections are clearly due to the fact that in the first we are combating an inanimate poison, in the second the toxic molecule is a living germ. If it is possible to demonstrate that the germs of distemper in virulent form have the power of reproduction, even after union with the antibodies, the whole theory of serum therapy in this disease falls to the ground.

Increase of the opsonic content of the blood is claimed for some sera by their manufacturers.

\section{Chemotherapy}

In the progress of civilization, where man has found his limitations, he has overcome them through his inventive genius. The earth, the sea, even the air has yielded to his dominion.

Chemotherapy is the logical outgrowth of a better understanding of disease. For centuries the ills of the body were shrouded in mystery and superstition. With a more perfect knowledge of the agents of infection and the limitations of the body's curative powers, medicine, following the course of human progress, has turned to a more powerful agent, the chemical germicide.

The most virulent disease germs can be destroyed by germicides. Antiseptics occupy the first place in our modern sanitation. They are effective for all parts of the body which can be reached by external application, but the toxicity which accompanies germicidal power in the ordinary germicide precluded its use internally, except in insufficient dosage. We find a very clear statement on the subject by 
Dr. Charles E. Simon at the beginning of his chapter on Chemotherapy.* He says:

"In the foregoing chapters we have seen that the animal body has at its disposal a mechanism by means of which it is not only capable in many instances of preventing infection, but even of overcoming this successfully if by any chance microorganisms have once passed the outer barriers and have gained a foothold in the tissues proper. We have also seen that it is possible to introduce some of those substances which the body makes use in its defence, from without, and that we can frequently turn the balance of the scales toward recovery in this manner, where, unaided, this would have been impossible, or attended by grave danger. Nevertheless we must admit that only too of ten allour efforts to combat infection by the body's own methods are in vain, and that in the majority of infectionsweare still far from a successful treatment.

"In view of the fact that in the test-tube we are able to destroy microorganisms with the greatest ease, by the aid of a large number of chemical preparations, the thought has naturally suggested itself whether it would not be possible to assist the normal defences of the body by the administration of some of these substances. We know as a matter of fact that the only specific medicinal treatment of the older Pharmacopoeia, viz., that of malaria by means of quinine, and of a syphilis by means of mercury, depends upon the destructive effect of the remedies in question upon the respective parasites. The recognition of this fact is of recent date, however, and does not form the basis upon which the treatment of these diseases was established. The discovery of the therapeutic properties of quinine and mercury, in other words, was not the outcome of logical thought and corresponding experimentation, but purely accidental.

"But the fact that it is actually possible to destroy some of the pathogenic microorganisms in the body of an infected individual by chemical means, would suggest that a similarly fortunate result might be achieved with other substances in the case of other organisms. The earlier investigations in this direction were, however, not crowned with success, and it was soon realized that in these studies also, accident would probably have to play a role, unless indeed every chemical substance were individually tested. The first and most

"Iufection and Immunity p 271. 
formidable difficulty which was encountered depended upon that fact that the majority of those substances which have strong germicidal properties, when tested outside of the animal body, were promptly rendered innocuous by entering into chemical combination with the albumins of the blood, when introduced into the body, and if a certain dose was exceeded their toxic effect was such that any attempt at destruction of the parasites would have carried with it the destruction of the host."

Thus we see that a germicide to be effective in internal medication must have a high bactericidal power and a low toxicity. It must not be affected adversely by the body fluids and on the other hand must not in any way injure the tissues or those substances in the body which are nature's protection against disease. In addition, and what is quite as important, it must be in such form as to insure a proper distribution throughout the system. Assimilation by the digestive organs is a simple and dependable test in this respect. Delcreo complies with these requirements in every particular. A description of this germicide will be found elsewhere.

The germicide Delcreo is sufficiently powerful to destroy the most virulent distemper infection. There is surplus power in the higher dosage. It has brought the treatment of the disease almost to the certainty of a mathematical problem. The doubtful quantity is the rapidity with which the virulent infection progresses. Here, as in treatment by the body's own methods, the animal's resistance and the power of the organisms are both factors. The toxic molecules of distemper in virulent form, once the infection has become general, are almost as rapidly destructive as some of the mineral poisons. If the infected animal's resistance is of a low order, it becomes a question of the number of hours that will elapse before destruction has gone so far that the disease can no longer be successfully treated There is no greater fallacy than the theory that "while there's life, there's hope." The animal's heart and lungs will function and consequently the dog will remain alive for a considerable period after the system has been injured beyond repair.

Early treatment is of great importance. In combating distemper with the animal's own antibodies, and it must be remembered that even when an antiserum is injected most.of the antibodies are formed in the system, a period of several 
days must elapse before the crisis. Much may happen during this time; destruction of the tissues, impairment of the organs, a general weakening of the system and the possibility of a secondary infection.

With the introduction of chemotherapy all this has been changed. The full power of the germicide can be applied by oral dosage in from fourteen to twenty-four hours, depending upon the animal's digestion, and serious injury prevented. This can be accomplished in a much shorter time by intravenous injection. In the early period of the disease the bacteria are comparatively few, but they multiply rapidly, not by tens and hundreds, but by millions. Distemper may be likened to a conflagration. In the beginning it is easily controlled; let it go unchecked, and there is no limit to its destructive force. Until the infection has become general the toxins are a help rather than a hindrance as they produce warning symptoms.*

With the experienced kennelmaster, who is careful of his dogs, early treatment is a simple matter. As a rule he is familiar with his dogs' past history. He knows which are susceptible and these are watched carefully for the first appearance of symptoms. With the veterinarian the case is different. Too often, through false notions of economy or otherwise, his client does not call for his services until the dog or dogs are really ill. In many instances the disease, by that time, has progressed beyond all hope of treatment. A closer cooperation between the dog owner and the veterinarian will eliminate needless delays.

If the germicide has been properly administered there is little danger of complications. Chemical germicides in proper dosage are generally destructive to all classes of pathogenic organisms. In this they are superior to serums which are specific. In testing germicidal solutions in the laboratory the results are the same whether the germicide is added to the water in the test tube before or after the entrance of the germs. The same is true of the body. If the germicide is already in the system, the germs which may find their way into the tissues proper are destroyed. Thus the danger of pneumonia and other secondary infections has been almost eliminated by chemotherapy.

*Chemotherapy is effective in semiparasitic infections because in most cases symptoms give warning in time to destroy the organisms before the toxic effect becomes serious. In infections of the true parasites, the germs often carry on their work unnoticed. In infections of the necroparasites destruction of the organisms does not end the danger from the toxins. 


\section{Directions}

$\mathrm{D}$

ELCREO is given by mouth but, in advanced* cases, time can be saved by administering it intravenously. The oral dosage should be continued however, for the antiseptic cleansing of the intestines. When given by mouth it is important to remember that to be effective the germicide must reach the blood stream. A close watch should be kept for the first signs of impaired digestion. Nausea, which is common in distemper, should be regarded with suspicion. It is an indication of a sensitive mucosa. While this is not necessarily serious, it is the first step towards impaired digestion.

Until the infection is under control, only a small amount of nourishment should be given, thus reserving the digestive organs for assimilation of the germicide. Avoid liquid foods or water in quantity as they dilute the germicide, preventing complete absorption. If treatment has been begun before the animal's appetite has become impaired, it may be given a small piecet of stale bread slightly moistened with sweet milk three times a day. The Delcreo may be poured over this at meal time, thus avoiding a liquid in the intestines, which may produce nausea. An equal amount of whiskey or brandy may be added for its favorable effect upon digestion and the nervous system. If the animal refuses its food forcible feeding must be resorted to. Sweet milk or broth should then be substituted for bread and milk. If food or medication is lost through vomiting, give a half dose of Delcreo with an equal amount of sweet milk for its antiseptic effect on the intestines. This should be repeated in an hour and if no further indications of nausea appear the regular treatment may be resumed.

The germicide should be given every two hours until the infection is under control. During convalescence it should be given at least three times a day. The average dose is

-This refers to the progression of the infection and not to the lapse of time. tone balf ounce for a dog weighing from twenty to thirty pounds. 
one teaspoonful for a dog weighing twenty pounds. For larger dogs in proportion. In severe cases the dose should be doubled. A mature dog of one of the smaller breeds can be given to advantage a proportionately larger dose than a puppy of equal weight belonging to one of the larger breeds.

Nursing puppies can be treated by administering the Delcreo to the dam in regular doses. In twenty-four hours the germicidal power of the drug will be transmitted through the milk. The puppies can be treated indivdually if preferred.

If digestion has become impaired, or, if through the progression of the infection it is apparent that the proper assimilation of the germicide is not obtained by oral dosage, or, if the disease is far advanced before treatment is begun, Delcreo should be administered by intravenous injection.

The needle should be inserted in the vein of the inner thigh. The hair should first be removed and the surface antiseptically cleansed. The germicide should be thoroughly shaken, diluted with an equal amount of sterile distilled water and strained through sterile gauze under strict aseptic precautions. The solution should be warmed to body temperature and slowly injected drop by drop. This operation should be performed by a specialist. The average dose is $10 \mathrm{c}$. c. of a fifty per cent solution for a dog weighing twenty-five pounds. If a second injection is necessary it should be administered twelve hours afterwards.

\section{Prophylaxis}

Delcreo may be used effectively as a preventative by giving it whenever there is a possibility of exposure to infection. The development of disease will be prevented as long as the germicide remains in the system. While the immunity is of short duration, it can be renewed as often as necessary and will be found convenient when exposing dogs to the strain of the bench show or railroad journey. When dogs are transported, treatment should begin twenty-four hours before shipment and should be renewed on the dog's arrival. Permanent immunity can be secured with no more inconvenience to the animal then preventive inoculation entails, by exposing the dog to infection and then administering curative treatment. Twelve hours in close proximity with an infected animal will usually insure contagion. The germicide should 
then be given promptly by oral dosage. Under this treatment the disease seldom passes the incubation stage, and symptoms may not appear.

This treatment is not advised nor is it necessary if the dog is in careful hands. Chemotherapy in distemper has shattered another truism "that an ounce of prevention is worth a pound of cure." The day is not far distant when to deliberately introduce the poison of disease into the system for prophylactic purposes, except where absolutely necessary, will be looked upon as a barbarism. 


\section{General Remarks}

$\mathrm{N}$ the preceding pages we have endeavored to tell, briefly, what distemper is, how it kills and how it may be controlled. Distemper is always a serious matter and not to be trifled with. There is only one safe rule in treating this disease and that is to stamp out the infection at the earliest possible moment. There is another reason for prompt treatment. While Delcreo will destroy the causative organisms, nature alone can repair the damage they have caused. Serious injury to the system and a protracted convalescence can be avoided by prompt treatment.

A healthy condition is a valuable ally because the system must absorb and distribute the germicide and the natural forces of the body resist the infection until the germicide is in control. This is particularly true in distemper because of the strain on the nervous system. Proper feeding, exercise, cleanliness, internal as well as external, and freedom from parasites are the first essentials. An antiseptic cleansing of the intestines and blood stream with Delcreo will be found beneficial.

Anything which will delay germicidal action should be avoided. There is a tendency on the part of new users of Delcreo to experiment, particularly if they have had success in some cases with other treatments. Their most serious error is to attempt to administer a purge or a vermifuge. During the progress of the disease the digestive organs are in a delicate condition and the administration of an irritant may be the last straw that will break down digestion. Delcreo can always be administered by intravenous injection, but if the digestive organs have ceased to function the dog may yet starve to death.

It must be remembered that all dogs are not alike. This of ten makes the reading of symptoms uncertain. In some breeds or strains, inbreeding has been practised to such an extent as to generally weaken the constitution of the 
species. There is also the same difference between individuals in dogs as there is in humans. A dog of great courage will often fight against disease until he is overwhelmed by it, while a less courageous dog of a nervous temperament will collapse before the infection has reached a serious stage. Two instances may be cited.

Our attention was called to a chow, which was in such a state of collapse from distemper, that a veterinarian was sent for to chloroform him. Delcreo was administered and the dog responded so promptly that it was evident that the dog's system had suffered little injury from the disease.

The second instance is one of very sad memory. An English setter, she will be found under No. 24151 in the Stud Book, had fought distemper with great courage for four long weeks. She had been the constant companion of the author for all of her two and one half years but it was evident that the final parting was very near at hand. Everything possible had been done for the dog, but it was in the early days of distemper knowledge, Torrey had not yet reported his investigations for the Continental and chemotherapy was unheard of; little could be done except careful nursing. As the dog had so few hours to live she was taken out into the orchard where she could feel the sunshine and look upon earth's brightness for the last time. It so happened that in a hedge row near where the dog lay, a mother quail and her brood had passed, and as the scent came faintly to the dog in her fever, she arose unsteadily to her feet and pointed, even the near approach of death could not quench her spirit. It was her loss which first prompted these studies. Looking back it is difficult to realize the dread in which the disease was held in those days.

\section{DELCREO}

$\mathrm{D}$ ELCREO has been made possible by a method of refining creosote which is a distinct advance over the German process under which much of the medicinal creosote was manufactured. Under the Delson process, not only are the irritating properties of the drug eliminated, but this refined creosote, which is a concentrate, shows a greater germicidal power than Creosote U. S. P.* The Creosote Delson is then combined in a glycerine emulsion

Phenol coefficint Creosote Delson 3.00 Crcosote U. S. P. 2.75, 
with the hypophosphites of calcium, sodium and potassium. Combinations of creosote and calcium have been attempted in the past on the theory that alkalies neutralize acids but much of the germicidal power was lost in the process. Creosote Delson withstands the neutralizing process.

Delcreo is nontoxic in the largest possible dose. Laboratory experiments show that to obtain a lethal dose over twenty-five times the capacity of the stomach must be given. It is difficult to determine the germicidal action in the body. Laboratory experiments in various dilutions indicate that the germicidal power of Delcreo is slightly in excess of carbolic acid.

\section{EQUINE INFLUENZA}

$7 \mathrm{HE}$ veterinarian will find Delcreo a valuable aid in the treatment of influenza in horses, sometimes called distemper, pinkeye, shipping fever, or stable pneumonia. Much of the information contained in this booklet will also apply to this disease.

It will be found convenient and economical to administer the germicide by intravenous injection.

\section{REPORTS FROM USERS}

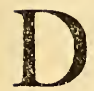

ELCREO was the outcome of animal experiments which were carried on in connection with the treatment of pneumonia and other diseases in children. It was desired to ascertain the effect of a larger dosage in virulent cases. Canine distemper was selected on account of the high death rate. The results of these experiments were reported in The American Field of July 1st, 1916, and created widespread interest among the kennel clubs and other organizations devoted to the dog. Fred M. Stephenson wrote "If you have discovered a cure for distemper you certainly will have accomplished a wonderful thing for all us dog lovers."

For some months the germicide was distributed, for experimental purposes, among universities and other institutions, and veterinarians and breeders, in order to obtain a thorough test, because results obtained in the laboratory or clinic are not always borne out in general practice. In the fall of 1916 Delcreo was put upon the market. From that 

mendation from all parts of the United States. Many of these are too long to print. We reproduce a few of the briefer communications.

\author{
ALFRED OBERLE \\ Doctor of Veterinary Medicine \\ BIOCHEMICAL ANALYSIS
}

New York City, Dec. 30, 1919

In replying to your communication as to results obtained in the treatment of canine distemper and pneumonia with Delcreo, I am breaking a life-long rule. I never before have written my approval of a preparation, but in the case of Delcreo I am justified. I hope the information will benefit others, and stimulate rescarch.

You will be interested in the following record which hegins in November, 1916, and continues through the next July, while I was connected with a City hosprial. The record shows 1014 cases of distemper, pneumonia and enteritis. These cases were treated with Delcreo as symptoms indicated recoveries, 911 ; deaths, 103; or, a death-rate of $10 \%$. And I am convinced that many of the fatalities could have been avoided, had the cases reached us in time.

My opinion of Delcreo is furthermore strengthened by results obtained since in my private practice, which are far more favorable.

I think the above record speaks for itself. Otherwise I would hesitate to write what might be construed as merely an indorsement of a preparation. I can truly say that Delcreo has put me in a position where I no longer dread distemper.

Yours truly,

ÁlFRED OBERLE.

\title{
Established 1899 VALLEY FORGE KENNELS
}

\section{ALL FARM RAISED STOCK \\ Phone-Norristown 1993-W Valley Forge Volcano at Stud Telegraph Norristown, Pa. \\ December 29,'19}

Enclosed please find my corrected check. Kindly credit me with same. I also want to say I used three bottles of Delcreo for five puppies three months old, that were shipped to me in the worst stage of distemper I ever saw on Oct. 18, and I sold every pup for Xmas in perfect health. I need not say it will always be in my kennels. Thanking you. I am, Yours very truly,

A. H. CROCKeTr.

\section{CHARLES A. HALEY \\ Utility Kennels Bath, N. Y.}

October 23, 1919

I am very glad to advise you that in my experience of more than thirty-five years with dogs, I have never before found a distemper cure that worked so quickly and effectively as Delcreo on the two puppies that I gave it to. Both are coming on finely and I do not think it wise to be without it

Thanking you in advance for your prompt attention and congratulating you on having a longfelt want, by dog men, I beg to remain, Sincerely yours,

Chas. A. Haley.

Amenia, N. Y., May 6, 1919

have just wired you to send me a bottle of Delcren for distemper on first train.

I have great faith in your medicine. Last year I had an airdale bitch taken very sick with apparently distemper. The odor was frightful, and she discharged from ears, nose and vagina, and when she tried to drink, strings of slime came from her mouth. Could not eat except when I would hold her head up and drop in little balls of chopped beef. Her tongue looked like a piece of calf's liver and finally about one inch of the end of it fell off. The vet made a number of visits and finally told me he could do no more for her. I had one half bottle of Delcreo on hand, and immediately began giving her heavy doses. I noticed an improvement within 24 hours, and she was well in less than two weeks.

I have since talked with veterinary, and people up on dogs and they seem to think she had black tongue, which I understand is almost always fatal. 
Medicine received in good time. Thanks for same.

I am having good luck with the medicine so far. Anybody could go through my kennel now and they never would think distemper had been there. Dogs are just as sleek as moles and look fit to take right out and show. I never saw dogs hold their flesh before, this is certainly a revelation to me. Anyway I am feeling very cheerful. I don't think chorea and paralysis follow so readily after Delcreo treatment, at least it does not look so to me now.

Thanking you for your promptness, believe me, Yours very truly,

WII.LIAM S. HAWKINS.

\section{WALLS KENNELS}

Mrs. A. E. WALls, Owner

\section{Cocker-Water}

SPANIELS

Camp Dennison, Ohio, February 12, 1919

I wish to thank you immensely for putting such a wonder on the market for sale as "Delcreo." It ought to be considered one of the wonders of the world, the dog world at least.

I am so happy to say "Little Teddy Cole" is alive and going to live. He had a very baf case of "pneumonia." I have given Delvreo faithfully every two hours. Thank you, my dog is on his feet. I remain, Yours very truly.

MRS. A. E. WALls.

\section{BRINGTON KENNELS}

January 26, 1919

It is with the greatest of pleasure that I can write you with the feeling of success that "Delcreo for Distemper" has done for my kennel. I can say one hundred per cent. cure has been the result of "Delcreo."

One wonderful case I should like to mention. I had a Pekinese develop distemper three days before whelping. I doubled the dose and she gave birth to 4 puppies and on the sixth day the fever had left her. I kept up the use of "Delcreo" and have some very valuable pups. And not a thing but "Delcreo." It was the best $\$ 1.50$ I ever spent.

I also use it when a dog goes off his feed and in a couple of days they are always back at the feed dish eating better than ever. I certainly shall stand by "Delcreo," first, last and always, for with its use, distemper, the worst death-dealer in dogdom, has been muzzled. It has two virtues. It takes the worry out of distemper as well as the germs.

You may use my name in connection with "Delcreo" at any time or place, for I am always ready to recommend it to any dog-owner. Respectfully yours.

112 Brighton Avenue, Allston, Mass. ERNEST R. Houghton,

Joseph B. Thomas, President

Middleburs, Va.

Wm. Du Pont, Jr., 1st Vice Pres.

Nontpelier Station, Va.
H. V. Huyler, 2nd Vice Pres*

21 Maiden Lane, New York City

R. M. Menefee, 3rd Vice Pres. Hawlin, Va.

\section{THE AMERICAN FOXHOUND CLUB}

\author{
Delegate to A. K. C. \\ Walter W. Stokes \\ 60 Proadway \\ New York City \\ E. Lester Jones \\ Secretary-Treasurer
}

Executive Committee

Frank D. Stuart

Middleburg, Va.

Malbon Gore Richardson

Upperville, Va.

R. L. Bohanmon, M. D.

Stamford, Conn.

November $28 \mathrm{th}, 1918$

Kindly send me six large kennel size bottles of your Delcreo. We have concluded after twu years of its use, that it is a necessity for success in raising Hounds. I ${ }^{\top}$ sincerely advise all dog breeders to use this remedy as directed. Yours very truly, $\rightarrow$ "Piedmont Hounds", FRANK D. STUART,

Niiddleburg, Va. 
South Heights, Pa., January 1, 191

Please find enclosed P. O. money order for $16 \mathrm{oz}$. of Delcreo and do please send by return mail as I have bought the entire stock of Delcreo from your agents in Pittsburg. My entire kennel has come down with distemper and I absolutely do not want to run out of this Delcreo for it is without an equal today in this disease. I have tried all their dope but nothing for me but it. It simply is a miracle. It keeps them whether they eat or not.

Respectfully, JAMES HENRY ELliotT.

\section{ST. BOTOLPH'S KENNELS \\ Cilf tondale, Mass., U. S. A.}

June 28,1918

Kindly give me kennel prices on Delcreo. I think we are the largest breeders of Boston Terriers in the country. It gives me great pleasure to write that I think Delcreo is the best medicine we have ever used.

You are at liberty to make whatever use you deem proper of this unsolicited testimonia!. With best wishes.

Sincerely,

EDWARD Axtell \& SON.

\section{STANDARD KENNELS \\ English-French Bulls-Bostons \\ White West Highland Terriers and Scottish Terriers}

Bedford, Ohio, April 29th, 1918

Allow me to say that Delcreo is simply wonderful, it has all the vaccines on the mar ket beaten a thousand ways, after a couple of doses you can see a marked improvement and we want to recommend most highly to any one who may have use for same. Wishing you success we are,

STANDARL KENNELS,

Very truly yours,

WM. LARSEN.

\section{HASSON KENNELS Cleveland, $\mathbf{O}$.}

October 26, 1917

Please send me one-half pint of your Delcreo. I can not do without it. It certainly works wonders I keep about 40 Bostons and as soon as a cold starts, I give Delcreo and they never get off feed and in a few days are all well again. Yours truly,

MRS. J. A. Hasson.

Courtland, Ala., Oct. 9, 1917

I am enclosing check for one dozen bottles of Delcreo. I find it the best medicine or dogs I have ever tried.

Yours truly,

W. D. GILCHRIST.

October 9, 1917

Enclosed plcase find check for Five dollars seventy-five cents for which send me at your early convenience one sixteen ounce bottle of Delcreo. Now I know what this remedy is, I cannot be without it. I brought thirteen West Highland Terriers through distemper last March without losing one, and some of the dogs were desperately sick too. If my puppies show the slightest sign of colds. or of being out of condition, a few doses of Delcreo puts them right again and in every way the remedy is invaluable to me. I am, Florence, Mass.

Very truly yours, Mrs. Eli/ABeth H. Warner,

\section{GLADSTONE SETTER KENNELS}

Fort Wayne, Ind., Sept. 18, 1917

I am enclosing check for $\$ 13.80$ for 3 pints of Delcreo which I received in good con dition. With what little experience I have had with Delcreo I think it the greatest specific for distemper I ever used. I will do all I can for Delcreo as I think it's every sportman's duty for the good of our most faithful friend The Dog. Wishing you success. Respectfully,

BEN. J. ANKENERUCK. 
I want to thank you for the new booklet on Delcreo for Distemper which I received this morning.

I also want to thank you for your remedy as I think Delcreo is the best specific for distemper as well as the best conditioner that it has ever been my good fortune to use, its action is wonderful and results are certain. I know because it saved a very fine Whitestone puppy for me when I had given her up to die, she was so weak that she could not stand when I gave her the first dose and inside of a week she was playing around the kennel yard. It certainly was a test as I had lost the other ten in the same litter before my first bottle of Delcreo reached me, you know it is a long way from New York out here and I was trying other things to stop the disease before I ordered Delcreo. I have my friend L. D. Adam, to thank, as well, as he told me over the phone what Delcreo would do, now I would not be without it. Again thanking you and wishing you the success you deserve, I am Yours truly,

L. D. W. Rowe.

Llewellyn

English and

Gordon Setters

Pointers

\section{J. D. ELLIS KENNEL \\ Field Trial and Shooting Dogs \\ Thompson, Ala.}

July 25th, 1917

I enclose check for 2 bottles Delcreo-I have used a few bottles with good results and have every doubt banished as to a conditioner, it will condition. Yours very truly,

J. D. ElLIS.

\title{
K. H. CLEAVER \\ Veterinary Surgeon
}

\author{
Reading, Pa., May 261917
}

Please send to my address one pint of Delcreo. I have given it a fair trial, and, find it what you claim.

Yours and so forth,

K. H. Cleaver.

Orange, Cal., February 22, 1917

The bottle of Delcreo which I recently received from you has already been put to very good use and in this case at any rate, has quite proven its worth.

A few days after it arrived I received a telephone message from a friend asking me to advise him regarding the treatment for his dog which seemed very ill. I called at his home, found the dog in the orchard where it had been lying for two days or morc. It was too sick to notice me, had considerable fever, and was discharging freely at the nose. Apparently a bad case of distemper.

Since my friend had not called a veterinary it occurred to me to try out the merits of Delcreo if he were willing, and at my suggestion we placed the dog in a warm, dry place and began according to directions.

Three days later he phoned me that his dog seemed "all right" again, was eating well and quite herself. He was somewhat astonished, but no more so than I. If Delcreo will always do the trick like this it is surely a most invaluable remedy and every kennel should have a supply.

Please send me another bottle that I may not be without it in the event that my druggist has any delay in procuring it for me.

Very truly yours,

RAY VAN BIBBER.

\section{OAK HILL KENNELS \\ L. D. ADAM}

Meridian, Okla

November 12th, 1916

When I received your last shipment of 12 bottles of Delcreo I had 15 cases of distem. per in the hospital all fully developed temperatures running from 102 to 105 . I had lost three cases before starting with this treatment and it looked as though several more of them would have to give it up, but since starting Delcreo I have not lost a case and am discharging them from the hospital every day well dogs.

There were three new cases started that I was able to stop in three days time without removing from their regular lot where they were associated with other dogs and there nave been no new cases for over a week now, and I am satisfied that I have it under control: some of these dogs have actually put on flesh while confined.

Kindly send ine 6 more bottles of Delcreo and mail bill for same. I have four bottles !eft and don't want to ever be without it on hand again.

Yours truly,

L. D. ADAM. 
P D-12、 





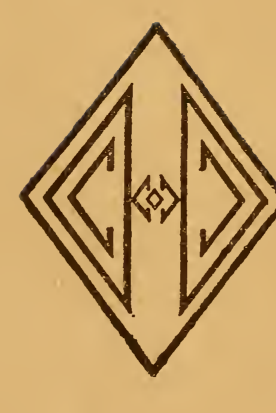







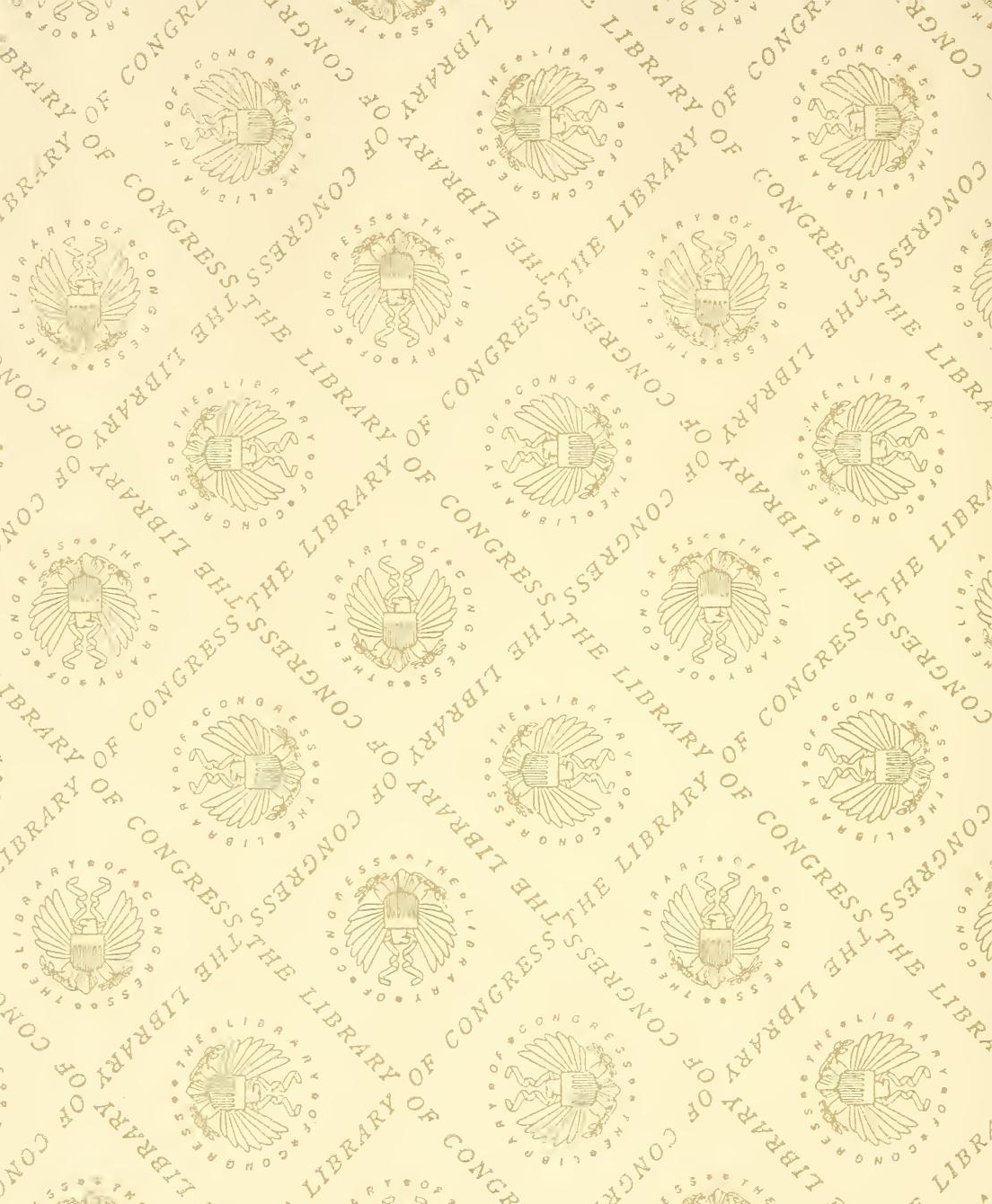





\section{LIBRARY OF CONGRESS}

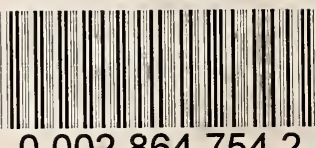

00028647542 